\title{
ОТВЕТСТВЕННОСТЬ ЗАКАЗЧИКА ПО ДОГОВОРУ АВТОРСКОГО ЗАКАЗА
}

\author{
В. Н. Белоусов \\ Байкальский государственный университет, г. Иркутск, Российская Федерация
}

\author{
Информация о статье \\ Дата поступления \\ 5 июня 2017 г. \\ Дата принятия к печати \\ 20 ноября 2017 г. \\ Дата онлайн-размещения \\ 27 ноября 2017 г.

\section{Ключевые слова} \\ Договор авторского \\ заказа; заказчик; автор; \\ гражданское правонарушение; \\ ответственность; вина; \\ неосторожность; умысел; \\ убытки
}

\begin{abstract}
Аннотация
В статье рассматриваются проблемы ответственности заказчика по договору авторского заказа, обосновывается отсутствие в гражданском законодательстве специальных норм об ограниченной ответственности заказчика за неисполнение или ненадлежащее исполнение своих обязанностей по договору авторского заказа. Исследуются предложенные в цивилистической литературе взгляды на понятие гражданско-правовой ответственности, определяются ее признаки и анализируются условия, необходимые для ее наступления, рассматриваются психологическая и объективистская концепции вины. В работе также представлены различные подходы, касающиеся целесообразности или нецелесообразности деления в гражданском праве умысла на прямой и косвенный, неосторожности на грубую и легкую (простую). Заключено, что определение размера ответственности заказчика исходя из учета форм и степеней вины при расчете ущерба, причиненного автору, не соответствует принципам неотвратимости и полного возмещения убытков.
\end{abstract}

\section{COMMISSIONER'S LIABILITY UNDER THE COMMISSIONING AGREEMENT}

\author{
Vladimir N. Belousov \\ Baikal State University, Irkutsk, Russian Federation
}

\section{Article info}

Received

June 5, 2017

Accepted

November 20, 2017

Available online

November 27, 2017

\section{Keywords}

Commissioning agreement; commissioner; author; civil offence; liability; guilt; negligence; guilty intent; economic loss

\begin{abstract}
The article considers the problems of the commissioner's liability under the commissioning agreement and substantiates the absence of special norms in the civil law regarding the limited liability of the commissioner for failure to [properly] perform their liability under the commissioning agreement. The author studies the approaches to the notion of the civil liability that are suggested in civil jurisprudence literature. He defines its signs and analyses the conditions necessary for liability incurrence, examines the psychological and objectivistic concepts of guilt. The author also presents different approaches that regard the expediency or inexpediency of subdividing the guilty intent into direct and eventual and of subdividing negligence into gross and ordinary. The author draws a conclusion that determination of the extent of the commissioner's liability, based on the forms and the degree of guilt when calculating the damage done to the author, does not comply with the principles of inevitability and the full compensation for damage.
\end{abstract}

В гражданском законодательстве не содержится специальных норм об ответственности заказчика за неисполнение или ненадлежащее исполнение договора авторского заказа. В то же время для автора по договору авторского заказа в ч. IV Гражданского кодекса РФ' ${ }^{1}$ предусмотрены особые

1 Гражданский кодекс Российской Федерации (часть четвертая) : федер. закон от 18 дек. 2006 г.

(C) В. Н. Белоусов, 2017 правила, устанавливающие ограниченную ответственность. Такой подход законодателя объясняется тем, что при заключении договора именно автор является «слабой стороной», нуждающийся в усиленной защите, поскольку ввиду низкой прогнозируемости творческого процесса нельзя быть

№ 230-Ф3 // Собрание законодательства РФ. 2006. № 52, ч. 1. Ст. 5496. 
уверенным, что при условии надлежащего исполнения им своих обязанностей произведение с заданными характеристиками будет создано. Следовательно, в случае привлечения заказчика к ответственности необходимо руководствоваться общими положениями об ответственности за нарушение обязательств.

Следует обратить внимание на то, что в действующем законодательстве отсутствует легальное определение понятия «гражданско-правовая ответственность». В цивилистической науке нет единства взглядов на понятие, условия наступления и формы гражданско-правовой ответственности. Данный феномен относится к числу наиболее обсуждаемых и дискуссионных [1, с. 33]. Это обстоятельство, безусловно, отрицательно сказывается и на регулировании отношений между автором и заказчиком в договоре авторского заказа в случае привлечения одной из сторон договора к ответственности.

Обратимся к ряду мнений, существующих в отечественной доктрине, относительно определения понятия гражданско-правовой ответственности. Впервые оно было предложено М. М. Агарковым. Он указывает, что «гражданский закон различает категории долга и ответственности. Исполняя обязательство добровольно, должник следует своему долгу. Если добровольность нарушается и должника принуждают к исполнению обязательства в первоначальном виде либо путем компенсации убытков, наступает ответственность» $[2$, с. 44].

С. Н. Братусь гражданско-правовую ответственность определял как меру «государственного или общественного принуждения», включая «понуждения должника к исполнению принятой на себя обязанности в натуре» [3]. Аналогичный вывод можно также встретить в трудах О. А. Симвалокова [4, с. 7].

О. А. Красавчиков гражданско-правовую ответственность рассматривал как установленную законом «неотвратимую негативную реакцию государства на гражданское правонарушение, выражающуюся в лишении определенных гражданских прав или возложении внеэквивалентных обязанностей имущественного характера» [5, с. 502]. Похожей позиции придерживался и О. С. Иоффе, определяя гражданско-правовую ответственность как «санкцию за правонарушение, вызывающую для нарушителя определенные последствия в виде лишения субъективных гражданских прав, либо возложение новых, либо дополнительных гражданско-правовых обязанностей» [6]. Подобные определения гражданско-правовой ответственности высказаны и другими авторами [7, с. 17].

Понятия гражданско-правовой ответственности, предложенные О. А. Красавчиковым и О. С. Иофрфе, представляются наиболее убедительными, поскольку они также считали элемент принуждения неотъемлемым свойством любой ответственности. О. С. Иофрфе отмечал, что и после совершения правонарушения его последствия могут быть устранены добровольно самим нарушителем, без вмешательства государственных органов, посредством одной лишь возможности принуждения и на основе осознания правонарушителем характера совершенных им действий и их отрицательного значения. Таким образом, «применение гражданско-правовых санкций иногда осуществляется не на основе прямого принуждения, а лишь благодаря его возможности... в силу односторонних или совместных действий участников соответствующих отношений» [6, с. 17-18].

Следовательно, не любая санкция является ответственностью, а лишь та, которая влечет дополнительные имущественные обременения (лишения) - уменьшение имущества должника. При этом уменьшение имущества должника является безэквивалентным, так как взамен должник ничего не получает [8, c. 191]. Уменьшение имущества должника производится помимо воли правонарушителя.

Учитывая изложенное, можно выделить следующие признаки (критерии) гражданско-правовой ответственности:

- применение санкций - мер принудительного характера;

- наступление ответственности, основанной на общественном осуждении;

- порождение дополнительных имущественных обременений (лишение, уменьшение имущества должника, которое является безэквивалентным);

- взыскивание помимо воли правонарушителя.

По общему правилу в юридической литературе в качестве условий, необходимых для наступления гражданско-правовой ответственности, выделяют:

- противоправный характер поведения лица, на которое предполагается возложить ответственность;

- причинение потерпевшему лицу вреда или убытков;

- причинная связь между противоправным поведением нарушителя и наступившими последствиями;

- вина правонарушителя [9; 10, с. 101]. 
Сходный вывод можно встретить и в судебной практике 2 .

В доктрине гражданского права отмечается, что самые многочисленные и сложные исключения из общих принципов привлечения к гражданско-правовой ответственности касаются наличия вины должника [11, с. 38]. В этой связи подробнее остановимся на рассмотрении вины как условия гражданско-правовой ответственности. В ст. 401 ГК РФ говорится, что лицо, не исполнившее обязательство либо исполнившее его ненадлежащим образом, несет ответственность при наличии вины (умысла или неосторожности), кроме случаев, когда законом или договором предусмотрены иные основания ответственности.

Следует заметить, что если в качестве заказчика по договору авторского заказа выступает юридическое лицо, осуществляющее предпринимательскую деятельность, то оно несет ответственность независимо от своей вины (п. 3 ст. 401 ГК РФ). Если заказчик не является лицом, преследующим коммерческие цели, то ответственность наступает лишь при наличии вины. Данное положение законодателя поддерживается и в юридической литературе [12].

В ст. 401 ГК РФ не дается понятия вины и ее форм, а лишь указывается, что вина может быть умышленной или причиняться по неосторожности. В науке гражданского права также отсутствует общепризнанное понимание вины.

Согласно первой позиции, вина рассматривается как психическое отношение лица к своему противоправному поведению [13; 14]. Другие ученые отстаивают «объективистскую» концепцию вины. По их мнению, вина должна определяться не через субъективные признаки, а объективно. При этом авторы ссылаются, в частности, на абзац 2 п. 1 ст. 401 ГК РФ, где указывается, что «лицо признается невиновным, если при той степени заботливости и осмотрительности, какая от него требовалась по характеру обязательства и условиям оборота, оно приняло все меры для надлежащего исполнения обязательства». Вина, по их мнению, это непринятие мер по предотвращению неблагоприятных последствий своего поведения [15].

Представляется, что следует поддержать представителей психологической теории вины, т. е. осознанного и сознательного отношения правонарушителя к своему противо-

2 Постановление Девятого Арбитражного апелляционного суда от 23 декабря 2013 г. № 09АП-41647/2013ГК по делу № A40-44828 / 2013 [Электронный ресурс] / / СПС «КонсультантПлюс». правному поведению и его результату. Вина свидетельствует об отрицательном отношении правонарушителя к интересам общества и государства, установленным обязательными правилами поведения. Психологические аспекты понятия вины разработаны наукой уголовного права, поэтому закономерно, что за неимением своих конструкций цивилисты стали обращаться к дефинициям уголовного закона [16, с. 108].

Понятия фоорм вины во многом напоминают понятие, приводимое в уголовном праве, хотя в гражданском праве имеются и свои особенности.

Прежде всего, в Уголовном кодексе PФ $^{3}$ различают прямой и косвенный умысел. Одна из особенностей вины в гражданском праве заключается в том, что цивилисты не выделяют вину с прямым или косвенным умыслом, а учитывают умысел вообще. В этой связи возникает вопрос, касающийся необходимости выделения формы и степени вины в гражданском праве. Будет ли такое деление вины способствовать справедливому определению размера ответственности заказчика в договоре авторского заказа?

Так, в доктрине высказывается мнение о целесообразности подразделения умысла на прямой и косвенный и в гражданском праве, поскольку исследователи полагают, что в ряде случае такая ситуация возникает. Например, о прямом умысле очевидно говорится в ст. 169 ГК РФ, так как антисоциальная сделка совершается с целью, противной основам правопорядка и нравственности. О вине с прямым умыслом говорится и в п. 4 ст. 401 ГК РФ. Здесь устанавливается, что заключенное заранее соглашение об устранении или ограничении ответственности за умышленное нарушение обязательств ничтожно.

О значимости и необходимости выделения в гражданском праве косвенного, а значит, и прямого умысла писала Ф. Л. Рабинович. В делах, где предметом спора является качество или комплектность продукции, вина, связанная с нарушением договорных обязательств, нередко имеет косвенный умысел, например факты ухудшения продукции и товаров в процессе транспортировки и хранения в результате неудовлетворительной упаковки [17, с. 82]. В настоящее время целесообразность выделения в гражданском праве прямого и косвенного умысла поддер-

${ }^{3}$ Уголовный кодекс Российской Федерации : федер. закон от 13 июня 1996 г. № 63-Ф3 // Собрание законодательства РФ. 1996. № 25. Ст. 2954. 
живает цивилист С. Киселев. По его мнению, «проступок признается совершенным С прямым умыслом, если лицо осознавало антиобщественность своего действия или бездействия и желало его наступления или предвидело возможность или неизбежность наступления антиобщественных последствий и желало их наступления» [18, с. 25]. Он также указывает, что «проступок признается совершенным с косвенным умыслом, если лицо осознавало антиобщественность своего действия или бездействия, предвидело возможность наступления антиобщественных последствий, не желало, но сознательно допускало эти последствия либо относилось к ним безразлично» [там же].

Тем не менее вина с прямым и косвенным умыслом встречается в гражданских правоотношениях значительно реже, чем в уголовных, поскольку гражданское право имеет дело с нормальными явлениями в сорере гражданского оборота, уголовное же право рассчитано на аномальные явления. В то же время в отдельных случаях и субъекты гражданского права умышленно нарушают права и охраняемые законом интересы других лиц.

Значительно чаще гражданские правонарушения сопровождаются виной по неосторожности. В уголовном праве неосторожность подразделяется на два вида: легкомыслие и небрежность. В гражданском праве неосторожность имеет две степени: грубую, «граничащую» с умыслом, и легкую (простую), «граничащую» с невиновностью $[19$, с. $214 ; 20$, с. 58].

Неосторожность в гражданском праве характеризуется большинством ученых как психическое отношение лица к своему противоправному поведению и его последствиям, т. е. лицо не предвидит возможности наступления последствий, не желает их наступления, но оно должно было и могло их предвидеть. Следовательно, неосторожная вина отличается от умышленной степенью предвидения. Неосторожность в гражданском праве свидетельствует об отсутствии должной внимательности, заботливости в поведении нарушителя. Поэтому необходимо определить ту меру заботливости, в пределах которой человек должен был предвидеть отрицательные последствия своих действий.

Дискуссионным в науке гражданского права является вопрос о том, какими критериями нужно руководствоваться, чтобы установить, могло ли лицо предвидеть последствия своих действий, и определить пределы предвидения, а значит, и ответственности. Суть полемики заключается в том, нужно ли учитывать (не учитывать) субъективные свойства и возможности конкретного правонарушителя или стоит исходить только из объективных обстоятельств.

Одни исследователи (И. Б. Новицкий и Л. А. Лунц [21], Г. К. Матвеев [22]) считали необходимым руководствоваться не субъективными свойствами нарушителя, а возможностями среднего гражданина или передового человека. Свой вывод они подтверждали тем, что если при определении возможности предвидения исходить из субъективного критерия, то нужно делать скидку на неумелость, неопытность. С применением же объективного критерия можно преодолеть безразличие и пассивность. Другие исследователи (Б. С. Антимонов [23], В. А. Рахмилович [24]) указывали, что для оценки предвидения последствий своих действий нужно исходить из субъективной способности конкретного лица. При этом они ссылались на то, что от гражданина нельзя требовать больше того, на что он способен. Каждый гражданин индивидуален, и критерий надлежащего поведения должен соответствовать возможностям конкретного лица. Кроме того, можно выделить третью группу ученых (В. Т. Смирнов и А. А. Собчак [25], Ю. Х. Калмыков [26]), которые полагали, что масштаб оценки поведения нарушителя должен быть объективно-субъективным. Этот вывод представляется наиболее обоснованным, поскольку учет лишь субъективного критерия противоречит нормативной природе права, устанавливающего общие правила поведения, и может привести к поглощению противоправности виновностью [27, с. 135]. Следовательно, целесообразно применение не субъективного или объективного, а объективно-субъективного критерия, построенного с учетом характера деятельности и конкретной обстановки, в которой она осуществляется, а также индивидуальных особенностей самого нарушителя. Например, в ст. 171 ГК РФ говорится, что «дееспособная сторона обязана... возместить другой стороне понесенный ею реальный ущерб, если дееспособная сторона знала или должна была знать о недееспособности другой стороны». Из этого следует, что законодатель предлагает учитывать одновременно оба критерия.

Переходя к разграничению легкой и грубой неосторожности, следует заметить, что в обоих случаях отсутствуют элементы наме- 
ренности. Поведение человека не направлено сознательно на правонарушение, но в то же время в поведении отсутствуют должные внимательность и осмотрительность, что характерно как для грубой, так и для простой неосторожности. Вместе с тем между этими двумя степенями вины существуют и определенные различия.

Ориентиры отграничения грубой неосторожности от легкой предлагаются В цивилистической науке. При грубой неосторожности в поведении лица отсутствует внимательность и осмотрительность. Легкая же неосторожность характеризуется тем, что лицо в некотором роде проявляет осмотрительность и внимательность, однако они недостаточны для того, чтобы избежать правонарушения. При этом нельзя не обратить внимание на нечеткость и расплывчатость данных критериев, сложность отграничения их друг от друга.

В юридической литературе (Г. К. Матвеев [22], В. П. Мозолин [28]) высказывалось мнение о целесообразности использования понятия «самонадеянность» для разграничения легкой и грубой неосторожности.

Самонадеянность характеризуется предвидением вредных последствий и легкомысленной надеждой на их предотвращение. Первый признак самонадеянности (предвидение последствий) сближает ее с умыслом, второй признак (отсутствие желания и допущение последствий) отличает ее от умысла [29, с. 295].

C. Киселев предлагает под легкой неосторожностью понимать проступок, когда лицо не предвидело возможности наступления антиобщественных последствий своего деяния (действий или бездействия), хотя при необходимой внимательности и предусмотрительности должно было и могло предвидеть эти последствия. Под грубой неосторожностью понимается проступок, когда лицо предвидело возможность наступления антиобщественных последствий своего деяния (действий или бездействия), но без достаточных к тому оснований самонадеянно рассчитывало на предотвращение этих последствий [18, с. 25].

Таким образом, деление вины в гражданском праве на формы и степени в некоторых случаях вполне оправданно. Однако вряд ли деление вины на степени является необходимым в случае привлечения к ответственности заказчика в договоре авторского заказа. Определение размера ответственности заказчика исходя из учета фрорм и степеней его вины при расчете убытков, причиненных автору, не соответствует принципам неотвратимости и полного возмещения вреда. На самом деле в случае нарушения заказчиком своих обязательств не имеет значения, с каким умыслом он действовал, поскольку основная цель привлечения его к ответственности - это взыскание убытков в полном объеме.

Следует отметить, что в ст. 15 ГК Рф отсутствует определение понятия «убытки», указано лишь, что́ понимается под реальным ущербом и упущенной выгодой. Ввиду отсутствия легальной дефиниции этого понятия необходимо обратиться к существующим мнениям на этот счет в отечественной доктрине.

И. Б. Новицкий и Л. А. Лунц под убытками понимали денежную оценку причиненного ущерба [21, с. 365]. В. В. Овсиенко убытками признает денежный эквивалент ущерба, а именно натурально-вещественные последствия нарушения обязательств [30, с. 19]. В. С. Евтеев определил убытки как «выраженные в денежной форме утраты или умаления имущественных благ или утраты возможности приобретения имущественных благ, которые являются результатом событий или неправомерных действий определенных лиц и в силу закона или договора подлежат возмещению потерпевшему лицу за счет причинившего лица с возможностью применения к последнему мер государственного принуждения» [31]. Последнее определение представляется наиболее удачным, поскольку более полно отражает специфические признаки убытков, а потому мы поддерживаем включение данного понятия в ст. 15 ГК Рф.

Ответственность заказчика по договору авторского заказа наступает в случае неисполнения или ненадлежащего исполнения им обязанностей. Основной (а в некоторых случаях и единственной) обязанностью заказчика в возмездном договоре авторского заказа является выплата автору вознаграждения.

При нарушении заказчиком обязанности, связанной с уплатой автору вознаграждения за созданное произведение науки, литературы, искусства, для заказчика наступает ответственность в виде возмещения причиненных автору убытков. Так, Арбитражным судом г. Москвы было установлено, что А. А. Шаткевич (автор) и ООО «ЭС ЭФ Продакшн» (заказчик) заключили договор авторского заказа, в соответствии с которым автор принял на себя обязательства по созданию оригинального литературного киносценария 
на русском языке аудиовизуального произведения - 12-серийного художественного фильма «Тайна кумира», а также по передаче заказчику исключительных имущественных авторских прав на сценарий и фильм, созданный на его основе. Во исполнение условий договора автор создал сценарий фильма и передал его заказчику. Вместе с тем заказчик свои обязательства по договору не исполнил: акты приема-передачи сценария не подписал, замечаний в срок на сценарий не предоставил, вознаграждение автору не выплатил. В результате суд решил взыскать с заказчика убытки в полном объеме ${ }^{4}$.

Таким образом, в случае привлечения заказчика по договору авторского заказа к ответственности следует руководствоваться общими положениями об ответственности за нарушение обязательств. Определение размера ответственности заказчика исходя из учета форм и степеней его вины нецелесообразно.

${ }_{4}$ Решение Арбитражного суда г. Москвы от 31 июля 2015 г. по делу № A40-35526/2015 [Электронный ресурс] / / СПС «КонсультантПлюс».

\section{СПИСОК ИСПОЛЬЗОВАННОЙ ЛИТЕРАТУРЫ}

1. Белоусов В. Н. Перспективы развития законодательства о гражданско-правовой ответственности застройщика / В. Н. Белоусов / / Нотариус. - 2013. - № 7. - С. 33-38.

2. Агарков М. М. Обязательство по советскому гражданскому праву / М. М. Агарков. - М. : Юрид. издво, 1940. - 192 с. - (Ученые труды / Всесоюз. ин-т юрид. наук НКЮ СССР ; вып. 3).

3. Братусь С. Н. Юридическая ответственность и законность: очерк теории / С. Н. Братусь. - М. : Юрид. лит., 1976. - 215 с.

4. Символоков О. А. Гражданско-правовая ответственность за нарушение обязательств при осуществлении предпринимательской деятельности : автореф. дис. ... канд. юрид. наук : 12.00 .03 / О. А. Символоков. - Волгоград, 2002. - 25 с. $544 \mathrm{c}$

5. Советское гражданское право : в 2 т. / под ред. О. А. Красавчикова. - М. : Высш. шк., 1985. - Т. 1. -

6. Иоффре О. С. Ответственность по советскому гражданскому праву / О. С. Иофрфе. - Л. : Изд-во Ленингр. ун-та, 1955. - 310 с.

7. Антимонов Б. С. Основания договорной ответственности социалистических организаций / Б. С. Антимонов. - М. : Госюриздат, 1962. - 175 с.

8. Канев Д. Р. Понятие гражданско-правовой ответственности в науке и законодательстве / Д. Р. Канев // Известия высших учебных заведений. Правоведение. - 2008. - № 4. - С. 184-200.

9. Грибанов В. П. Осуществление и защита гражданских прав / В. П. Грибанов. - М. : Статут, 2000. - 411 с.

10. Романенкова Н. Д. Правовой статус застройщика по договору участия в долевом строительстве многоквартирных домов и (или) иных объектов недвижимости : дис. ... канд. юрид. наук : 12.00 .03 / Н. Д. Романенкова. - М., 2009. - 236 с.

11. Гаврилов Э. Договоры заказа на создание авторских произведений / Э. Гаврилов, К. Гаврилов // Хозяйство и право. - 2013. - № 3. - С. 28-45.

12. Сергеев А. П. Право интеллектуальной собственности в Российской Федерации / А. П. Сергеев. - М. : Проспект, 1996. - 704 с.

13. Малеин Н. С. Вина как необходимое условие имущественной ответственности / Н. С. Малеин // Советское государство и право. - 1971. - № 2. - С. 28-35.

14. Матвеев Г. К. Психологический аспект вины советских юридических лиц / Г. К. Матвеев / / Советское государство и право. - 1978. - № 8. - С. 39-47.

15. Брагинский М. И. Договорное право / М. И. Брагинский, В. В. Витрянский. - М. : Статут, 2003. - Т. 1 : Общие положения. -848 с.

16. Болдинов В. М. Ответственность за причинение вреда источником повышенной опасности / В. М. Болдинов. - М. : Юрид. центр Пресс, 2002. - 370 с.

17. Рабинович Ф. Л. Вина как основание договорной ответственности предприятий / Ф. Л. Рабинович. - М. : Юрид. лит., 1975. - 168 с.

18. Киселев С. Формы и виды вины в гражданских правоотношениях / С. Киселев / / Российская юстиция. 2000. - № 4. - С. 25.

19. Мейер Д. И. Русское гражданское право : в 2 ч. - М. : Статут, 2003. - Ч. 1. - 831 с.

20. Дмитриева О. В. Ответственность без вины в гражданском праве / О. В. Дмитриева. - Воронеж : Воронеж. высш. шк. МВД РФ, 1997. - 136 с.

21. Новицкий И. Б. Общее учение об обязательстве / И. Б. Новицкий, Л. А. Лунц. - М. : Госюриздат, 1950. -416 c.

22. Матвеев Г. К. Основания гражданско-правовой ответственности / Г. К. Матвеев. - М. : Юрид. лит., 1970. $-311 \mathrm{c}$.

23. Антимонов Б. С. Значение вины потерпевшего при гражданском правонарушении / Б. С. Антимонов. М. : Госюриздат, 1950. -275 с.

24. Рахмилович В. А. К вопросу о содержании и значении гражданской вины / В. А. Рахмилович / / Ученые записки Всесоюзного юридического заочного института / ред. Б. С. Утевский. — М. : Юрид. изд-во, 1958. Вып. 5 : Вопросы гражданского права. - С. 117-138. 
25. Смирнов В. Т. Общее учение о деликтных обязательствах в советском гражданском праве / В. Г. Смирнов, А. А. Собчак. - Л. : Изд-во Ленингр. ун-та, 1983. - 152 с.

26. Калмыков Ю. Х. Возмещение вреда, причиненного имуществу / Ю. Х. Калмыков. - Саратов : Изд-во Сарат. ун-та, 1965. - 72 с.

27. Иоффре О. С. Обязательственное право / О. С. Иоффре. - М. : Юрид. лит., 1975. - 880 с.

28. Научно-практический комментарий к Гражданскому кодексу Российской Федерации, части первой / под ред. В. П. Мозолина, М. Н. Малеиной. - М. : Норма, 2004. - 848 с.

29. Матвеев Г. К. Вина в советском гражданском праве / Г. К. Матвеев. - Киев : Изд-во Киев. ун-та, 1955. - 307 c.

30. Овсиенко В. В. Проблемы возмещения убытков в хозяйственном праве : автореф. дис. ... д-ра юрид. наук : 12.00 .03 / В. В. Овсиенко. - Харьков, 1972. - 31 с.

31. Евтеев В. С. Возмещение убытков как вид ответственности в коммерческой деятельности / В. С. Евтеев. - М. : Зерцало-М, 2005. - 184 с.

\section{REFERENCES}

1. Belousov V. N. Prospects of development of the legislation about civil responsibility of the builder. Notarius $=$ Notary, 2013, no. 7, pp. 33-38. (In Russian).

2. Agarkov M. M. Obyazatel' stvo po sovetskomu grazhdanskomu pravu [Liability under the Soviet Civil Law]. Moscow, Yuridicheskoe izdatel'stvo Publ., 1940. 192 p. Series «Learned Writings of All-Union Institute of Legal Sciences of The People's Commissariat for Justice of the USSR», iss. 3.

3. Bratus' S. N. Yuridicheskaya otvetstvennost' i zakonnost': ocherk teorii [Liability and Legality: an Outline of Theory]. Moscow, Yuridicheskaya Literatura Publ., 1976. 215 p.

4. Simvolokov O. A. Grazhdansko-pravovaya otvetstvennost' za narushenie obyazatel' stv pri osushchestvlenii predprinimatel'skoi deyatel'nosti. Avtoref. Kand. Diss. [Civil Liability for Violation of Obligations During Business Activities. Cand. Diss. Thesis]. Volgograd, 2002. 25 p.

5. Krasavchikov O. A. (ed.). Sovetskoe grazhdanskoe pravo [Soviet Civil Law]. Moscow, Vysshaya shkola Publ., 1985. Vol. 1. 544 p.

6. loffe O. S. Otvetstvennost' po sovetskomu grazhdanskomu pravu [Liability under the Soviet Civil Law]. Leningrad State University Publ., 1955. 310 p.

7. Antimonov B. S. Osnovaniya dogovornoi otvetstvennosti sotsialisticheskikh organizatsii [Foundations of Contractual Liability of Socialist Organizations]. Moscow, Gospolitizdat Publ., 1962. 175 p.

8. Kanev D. R. The Notion of Civil Liability in Science and Law. Izvestiya Vysshikh uchebnykh zavedenii. Pravovedenie = Proceedings of Higher Education Institutions. Pravovedenie, 2008, no. 4, pp. 184-200. (In Russian).

9. Gribanov V. P. Osushchestvlenie i zashchita grazhdanskikh prav [Exercise and Protection of Civil Rights]. Moscow, Statut Publ., 2000. 411 p.

10. Romanenkova N. D. Pravovoi status zastroishchika po dogovoru uchastiya $v$ dolevom stroitel'stve mnogokvartirnykh domov i (ili) inykh ob»ektov nedvizhimosti. Kand. Diss. [Legal Status of the Developer under the Contract for Participation in the Shared Construction of Apartment Buildings and (or) Other Real Estate Pieces. Cand. Diss.]. Moscow, 2009. 236 p.

11. Gavrilov E., Gavrilov K. Commissioning agreements for author's works. Khozyaistvo i pravo = Economy and Law, 2013, no. 3, pp. 28-45. (In Russian).

12. Sergeev A. P. Pravo intellektual'noi sobstvennosti v Rossiiskoi Federatsii [Intellectual Property Law in the Russian Federation]. Moscow, Prospekt Publ., 1996. 704 p.

13. Малеин Н. C. Guilt as an Essential Prerequisite of Property Liability. Sovetskoe gosudarstvo i pravo $=$ Soviet State and Law, 1971, no. 2, pp. 28-35. (In Russian).

14. Malein N. S. The Psychological Aspect of Guilt of the Soviet Legal Entities. Sovetskoe gosudarstvo i pravo = Soviet State and Law, 1978, no. 8, pp. 39-47. (In Russian).

15. Braginskii M. I., Vitryanskii V. V. Dogovornoe parvo [Contract Law]. Moscow, Statut Publ., 2004. Vol. 1. 688 p.

16. Boldinov V. M. Otvetstvennost' za prichinenie vreda istochnikom povyshennoi opasnosti [Responsibility for Harm Caused by a Sourse of Increased Danger]. Moscow, Yuridicheskii tsentr Press, 2002. 370 p.

17. Rabinovich F. L. Vina kak osnovanie dogovornoi otvetstvennosti predpriyatii [Guilt as the Basis of Contractual Liability of Companies]. Moscow, Yuridicheskaya Literatura Publ., 1975. 168 p.

18. Kiselev S. Forms and Types of Guilt in Civil Legal Relations. Rossiiskaya yustitsiya $=$ Russian Justice, 2000, no. 4, p. 25. (In Russian).

19. Meier D. I. Russkoe grazhdanskoe pravo [Russian Civil Law]. Moscow, Statut Publ., 2003. Pt. 1. 831 p.

20. Dmitrieva O. V. Otvetstvennost' bez viny $v$ grazhdanskom prave [Liability without Fault in Civil Law]. Voronezh Higher School of the Russian Internal Affairs Ministry Publ., 1997. 136 p.

21. Novitskii I. B., Lunts L. A. Obshhee uchenie ob obyazatelstve [General Studies on the Obligation]. Moscow, Gosyurizdat Publ., 1950. 416 p.

22. Matveev G. K. Osnovaniya grazhdansko-pravovoi otvetstvennosti [Foundations of Civil Liability]. Moscow, Yuridicheskaya Literatura Publ., 1970. 311 p.

23. Antimonov B. S. Znachenie viny poterpevshego pri grazhdanskom pravonarushenii [The Meaning of the Guilt of the Wronged Person in Civil Offence]. Moscow, Gospolitizdat Publ., 1950. 275 p.

24. Rakhmilovich V. A. The Question of the Content and Meaning of Civil Guilt. In Utevskii B. S. (ed.). Uchenye zapiski Vsesoyuznogo yuridicheskogo zaochnogo instituta [Bulletin of the All-Union Correspondence Legal Institute]. Moscow, Yuridicheskoe izdatel'stvo Publ., 1958, iss. 5, pp. 117-138. (In Russian). 
25. Smirnov V. T., Sobchak A. A. Obshchee uchenie o deliktnykh obyazatel'stvakh v sovetskom grazhdanskom prave [General Doctrine of Tort Liability in Soviet Civil Law]. Leningrad State University Publ., 1983. 152 p.

26. Kalmykov Yu. Kh. Vozmeshchenie vreda, prichinennogo imushchestvu [Compensation for Harm Caused to Property]. Saratov State University Publ., 1965. 72 p.

27. loffe O. S. Obyazatel' stvennoe pravo [Law of Obligations]. Moscow, Yuridicheskaya Literatura Publ., 1975. $880 \mathrm{p}$.

28. Mozolin V. P., Maleina M. N. (eds). Nauchno-prakticheskii kommentarii k Grazhdanskomu kodeksu Rossiiskoi Federatsii, chasti pervoi [Scientific Practical Commentary to the Civil Code of the Russian Federation, Part 1]. Moscow, Norma Publ., 2004. 848 p.

29. Matveev G. K. Vinav sovetskom grazhdanskom prave [Guilt in the Soviet Civil Law]. Kiev University Publ., 1955. $307 \mathrm{p}$.

30. Ovsienko V. V. Problemy vozmeshcheniya ubytkov v khozyaistvennom prave. Avtoref. Dokt. Diss. [Problems of Compensation for Losses in Business Law. Doct. Diss. Thesis]. Khar'kov, 1972. 31 p.

31. Evteev V. S. Vozmeshchenie ubytkov kak vid otvetstvennosti v kommercheskoi deyatel' nosti [Compensation for Losses as a Type of Liability in Business Activities]. Moscow, Zertsalo-M Publ., 2005. 184 p.

\section{Информация об авторе}

Белоусов Владимир Николаевич - старший преподаватель, кафедра гражданского права и процесса, Байкальский государственный университет, 664003, г. Иркутск, ул. Ленина, 11, e-mail: vladimir89.89@inbox.ru.

\section{Для цитирования}

Белоусов В. Н. Ответственность заказчика по договору авторского заказа / В. Н. Белоусов // Известия Байкальского государственного университета. - 2017. - T. 27, № 4. - C. 554-561. - DOI: 10.17150/2500-2759.2017.27(4).554-561.

\section{Author}

Vladimir N. Belousov - Senior Lecturer, Department of Civil Law and Procedure, Baikal State University, 11 Lenin St., 664003, Irkutsk, Russian Federation, e-mail: vladimir89.89@inbox.ru

\section{For citation}

Belousov V. N. Commissioner's Liability under the Commissioning Agreement. Izvestiya Baykal'skogo gosudarstvennogo universiteta $=$ Bulletin of Baikal State University, 2017, vol. 27, no. 4, pp. 554-561. DOI: $10.17150 / 2500-2759.2017 .27(4) .554-561$. 